\title{
PHYSICAL AND MECHANICAL PROPERTIES OF PARTICLEBOARD FROM Eucalyptus grandis PRODUCED BY UREA FORMALDEHYDE RESIN WITH $\mathrm{SiO}_{2} \mathrm{NANOPARTICLES}$
}

\author{
Ana C. M. Valle', Bruno S. Ferreira ${ }^{1}$, Glaucia A. Prates ${ }^{1,2}$, Danielle Goveia ${ }^{1,3}$, \\ Cristiane I. de Campos ${ }^{1 *, 4}$
}

${ }^{1 *}$ Corresponding author. UNESP - Universidade Estadual Paulista "Julio de Mesquisa Filho" - Câmpus de Itapeva, Faculdade de Engenharia/ Itapeva - SP, Brasil. E-mail: cristiane.campos@unesp.br | ORCID: https://orcid.org/0000-0001-9669-6820

\section{KEYWORDS}

thickness swelling, wood-based products, adhesives.

\begin{abstract}
The use of nanoparticles appears to be a feasible option for improving the quality of a range of wood-based products. Studies show that they can improve both the physical and mechanical properties of wood and wood-based products. This preliminary study aimed to analyze the influence of $\mathrm{SiO}_{2}$ nanoparticles on the physical and mechanical properties of wood particleboard. To this end that, panels were produced without the addition of $\mathrm{SiO}_{2}$ nanoparticles and with the addition of $4 \%$ by mass of the urea formaldehyde adhesive used for its production. The results showed that panels produced with the nanoparticles $42 \%$ reduction in thickness swelling of the panel. Therefore, the dimensional stability of the panels without decreasing mechanical properties, even when used in small proportions.
\end{abstract}

\section{INTRODUCTION}

Nanoparticles have been the object of study in wood and wood-based products in order to improve some of their physical and mechanical properties. results have been obtained when using these nanoparticles as additives in resins used in the consolidation of wood panels, especially urea formaldehyde resin.

In the work carried out by Rangel et al. (2017), Eucalyptus urophylla particleboards were produced with two density variations. Medium-density particleboards did not present satisfactory results in terms of physical properties, but produced good results with regards to mechanical properties when compared to normative values. On the other hand, high-density panels met both physical and mechanical normative requirements. The authors concluded that eucalyptus wood can be used to produce particleboards.

Urea formaldehyde resin has been widely used in the wood-based panel industry for over 100 years. Urea formaldehyde resins have advantages over other adhesives, such as easy handling, low cost, and good performance in wood panels (Lubis et al., 2017). This superior performance in panel production is due to its high reactivity and costeffective properties. Its disadvantages include low moisture resistance and high emission of formaldehyde. Nowadays, this technology offers the possibility of using additives such as nanoparticles, which have large surface areas and can incorporate new or even modify important properties of the resins, such as reactivity. $\mathrm{SiO}_{2}$ nanoparticles incorporated in urea formaldehyde resin have been reported to be an option for improving the mechanical properties of this resin (Roumeli et al., 2012).

Thickness swelling is another factor of wood-based panels that have been studied in order to decrease its occurrence. Iwakiri et al. (2012) produced homogeneous and multi-layered particleboards with Melia azedarach and Pinus taeda wood by varying the resin content. It was verified that the increase in resin content improved the particleboard performance in terms of water absorption and thickness swelling. One option is to explore the solutions that nanotechnology can offer. The small size of nanoparticles allows them to penetrate deep into the wood, effectively modifying the surface chemistry, resulting in an increased protection against moisture (Mantanis \& Papadopoulos, 2010).

Taghiyari \& Bibalan (2013) incorporated copper nanoparticles into the particles of wood particleboard, which resulted in an improvement in heat transfer during the hot-pressing process, consequently reducing the

\footnotetext{
${ }^{1}$ UNESP - Universidade Estadual Paulista “Julio de Mesquisa Filho" - Câmpus de Itapeva, Faculdade de Engenharia/ Itapeva - SP, Brasil.

${ }^{2}$ Faculty of Agricultural and Veterinary Sciences. University São Paulo State University - UNESP/ Jaboticabal - SP, Brazil.

${ }^{3}$ Faculty of Pharmaceutical Sciences, São Paulo State University - UNESP/ Araraquara - SP, Brazil.

${ }^{4}$ Department of Mechanical Engineering, Faculty of Engineering. São Paulo State University - UNESP Guaratinguetá - SP, Brazil.
}

Area Editor: Danilo Florentino Pereira

Received in: 5-3-2018

Accepted in: 4-13-2020 
pressing time. Furthermore, the addition of nanoparticles improved the modulus of elasticity (MOE) of the panels and decreased water absorption, which is an important factor for improving the dimensional stability of the panel.

In the study by Mantanis \& Papadoulos (2010) with medium density particleboard (MDP), oriented strandboard (OSB), and medium density fiberboard (MDF), the nanotechnological compound SurfaPore ${ }^{\mathrm{TM}} \mathrm{W}$, which contains three different sizes of nanoparticles, was added to this compound as a nano-emulsion of paraffin. The results showed a significant reduction in the thickness swelling of panels treated with the nano-emulsion of paraffin.

The study of wood-based panels has gained prominence in recent years, specifically with the goal of improving the physical and mechanical properties of panels. Different materials have been incorporated into the panels where reinforcements such as fibers and special resins can be highlighted, in addition to different treatments, in order to improve some of its properties.

In a study on the use of low-density wood residues and two variations of polyurethane resin, Christoforo et al. (2015) demonstrated the efficiency of these new adhesives in the production of wood particulate panels, both in terms of physical and mechanical performance. The authors have proven that the addition of these new constituents as reinforcement, or even as another adhesive, has improved the overall properties of the panels.

Ferreira et al. (2017) carried out heat treatment in plywood and obtained an improvement in dimensional stability without decreasing the mechanical properties. Silva et al. (2019) studied the addition of $\mathrm{ZnO}$ nanoparticles to eucalyptus particleboards, and the results showed that homogenous heat distribution occurred during the pressing stage, which improved physical properties, decreasing the $24 \mathrm{~h}$ swelling from $22.2 \%$ to $14.9 \%$, and the $24 \mathrm{~h}$ absorption from $30.29 \%$ to $21.0 \%$. Moreover, the modulus of rupture (MOR) values increased from 11.3 MPa to $14.5 \mathrm{MPa}$, and the modulus of elasticity (MOE) increased from $1880 \mathrm{MPa}$ to $2510 \mathrm{MPa}$.

Kumar et al. (2013) studied the use of aluminum oxide nanoparticles mixed with urea formaldehyde resin in the production of MDF. The results showed that the addition of these nanoparticles improved heat transfer during the curing stage, thus reducing the pressing time. This also influenced the physical and mechanical properties of the fiberboard by enhancing its MOR, MOE, and thickness swelling.

Christoforo et al. (2016) evaluated the mechanical properties of particulate panels of Pinus wood and polyurethane resin reinforced with laminated composites in an epoxy matrix, and obtained results much higher than the normative specifications in static flexural tests for MOE and MOR determination.

Nanoparticles have also been a good alternative for increasing wood-based product biodeterioration resistance by fungi. This can be observed in the study by Taghiyari et al. (2014), who used silver and copper nanoparticles, which showed a large decrease in the growth of fungal colonies exposed to particleboard treated with nanoparticles.

In the study performed by Zeki \& Akbulut (2015), wood particleboards were reinforced with nanoparticles of $\mathrm{SiO}_{2}, \mathrm{Al}_{2} \mathrm{O}_{3}$, and $\mathrm{ZnO}$ at loading levels of $0 \%, 1 \%$, and $3 \%$.
The authors concluded that the use of nanomaterials for the reinforcement of panels affected the physical-mechanical performance, indicating feasibility in the use of these materials as reinforcements in wood particleboards.

Nosál' \& Reinprecht (2017) added zinc oxide nanoparticles to melamine-formaldehyde resin used to impregnate coating papers in panels. The objective of the use of the nanoparticles was to improve the properties of the panels against the attack of bacteria and molds, which was improved by up to $50 \%$.

Rangavar \& Hoseiny (2015), when treating particleboard with urea-formaldehyde resin and copper nanoparticles, an increase in the MOR value (12.41 MPa) of the treated panels ( $6 \%$ of nano-copper) with respect to the control panels $(11.05 \mathrm{MPa})$ and it was. The best internal bonding result was obtained for panels treated with $8 \%$ nano-copper (0.32 $\mathrm{MPa})$.

Based on the foregoing information, this preliminary study aimed to evaluate the influence on the physical and mechanical properties of wood particleboards by adding $\mathrm{SiO}_{2}$ nanoparticles in the urea formaldehyde adhesive used in the production of these boards.

\section{MATERIAL AND METHODS}

In this study, particleboards were produced with Eucalyptus grandis particles and urea formaldehyde adhesive. $\mathrm{SiO}_{2}$ nanoparticles that were $30 \mathrm{~nm}$ in length were added to the adhesive. These nanoparticles were characterized in earlier studies (Goveia et al., 2011). However, panels without the addition of nanoparticles were also produced. Four panels of each type were produced with measurements of $420 \mathrm{~mm} \times 420 \mathrm{~mm} \times 13 \mathrm{~mm}$.

Initially, Eucalyptus grandis wood was processed using a laboratory chipper with four knives to produce chips. These chips were then converted into particles using a Wiley mill (Thomas Scientific). Subsequently, the particles were passed through in a sieve shaker, where particles of $9,16,35$, and 60 mesh were obtained.

For the formation of the mattress, $1330 \mathrm{~g}$ of particles was used per panel. The core layer was made using $1000 \mathrm{~g}$ of 9- and 16-mesh particles in equal proportions. Each of the two outer layers was made using $165 \mathrm{~g}$ of $35-$ and $60-$ mesh particles, in equal proportions.

The adhesive used contained $10 \%$ of urea formaldehyde resin based on the particle dry weight, $2 \%$ water, and $1 \%$ catalyst (ammonium sulfate) for the outer layers, and $8 \%$ of urea formaldehyde resin based on the particle dry weight, $2 \%$ water, and $1 \%$ catalyst for the core layers. The nanoparticles were added to the adhesive in a proportion of $4 \%$ relative to the urea formaldehyde resin weight.

Firstly, the adhesive was mixed with the particles until complete homogenization was achieved. Then, the blend was placed in the forming box and compressed to obtain the mattress (Figure 1a). Following compaction, the forming box was removed (Figure 1b), and the mattress was subjected to hot-pressing for $10 \mathrm{~min}$ ( 3 cycles of $180 \mathrm{~s}$ with two intervals of $30 \mathrm{~s}$ between them) at a temperature of $160{ }^{\circ} \mathrm{C}$ and pressure of $40 \mathrm{kgf} \mathrm{cm}^{-2}$ in a hydraulic press (Figure 1c). 


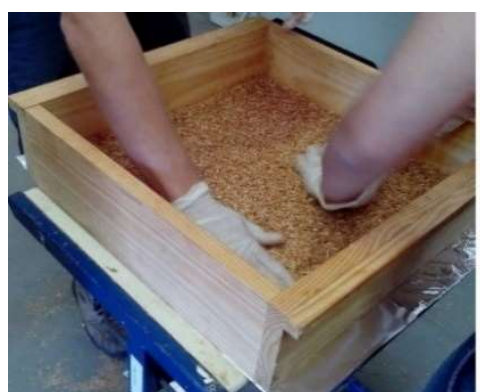

(a)

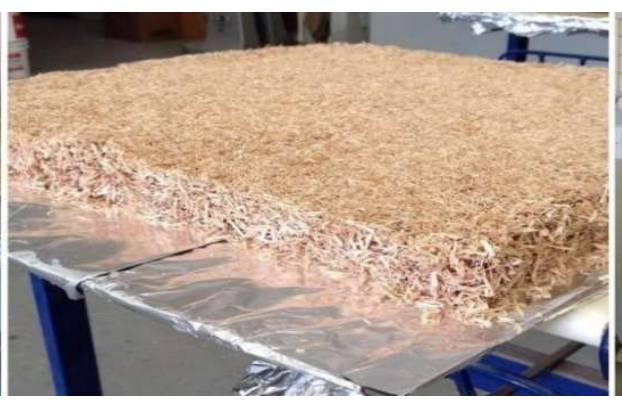

(b)

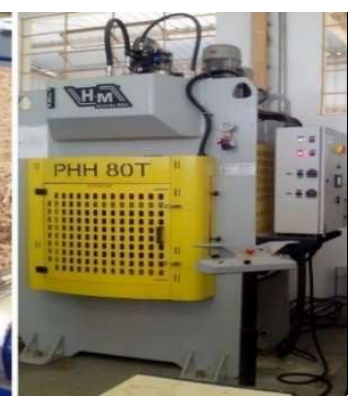

(c)

FIGURE 1. Production of the particleboards: (a) forming box, (b) particle mattress, and (c) hot-pressing.

The panels were placed in a climatic chamber until the completion of the resin curing process for $72 \mathrm{~h}$, at a relative humidity of $60 \%$ and temperature of $25{ }^{\circ} \mathrm{C}$. Four panels were produced with the addition of nanoparticles and four without the addition of nanoparticles, in order to obtain the samples necessary to perform characterizations according to the normative document.

The following tests were carried out for physical and mechanical characterization of the panels: thickness swelling for $24 \mathrm{~h}$ (EN 317 - 2000), moisture content (EN 322 - 2000), bulk density (EN 323 - 2000), perpendicular tension or internal bonding (EN 319 - 2000), and static bending (EN $310-2000)$ in order to determine the modulus of rupture (MOR) and modulus of elasticity (MOE).

The results were analyzed via a hypothesis test, i.e., the $\mathrm{t}$-distribution test at a 5\% significance level, using the $\mathrm{R}$ software version 2.12.2.

\section{RESULTS AND DISCUSSION}

Table 1 shows the mean and standard deviation of the physical tests performed.

TABLE 1. Results of physical tests.

\begin{tabular}{cccc}
\hline Situations & Density $\left(\mathbf{k g ~ m}^{-3}\right)$ & Moisture Content (\%) & Thickness Swelling (\%) \\
\hline \multirow{2}{*}{$0 \% \mathrm{SiO}_{2}$-Nano } & $867 \mathrm{a}^{1}$ & $6.9 \mathrm{a}$ & $62 \mathrm{a}$ \\
& $(9 \%)^{2}$ & $(7 \%)$ & $(29 \%)$ \\
$4 \% \mathrm{SiO}_{2}$-Nano & $866 \mathrm{a}$ & $6.5 \mathrm{a}$ & $37 \mathrm{~b}$ \\
& $(14 \%)$ & $(10 \%)$ & $(24 \%)$ \\
\hline
\end{tabular}

${ }^{1}$ Means followed by the same letter were not significantly different at a $5 \%$ significance level.

${ }^{2}$ Values in parentheses show the coefficient of variation.

The density and moisture content values were statistically equal at a significance level of $5 \%$. The panels produced may be classified as high-density panels according to EN 1058 (2003), which ranked medium density particleboard as being between 500 and $800 \mathrm{~kg} \mathrm{~m}^{-3}$.

The average values of thickness swelling were high; however, for dry conditions including for use in furniture, EN 312 has no normative limitation. These results may be caused by the absence of paraffin emulsion in the manufacturing process because it increases the dimensional stability of the panel or the lower amount of resin in the core layer. An alternative for improving the performance of thickness swelling further is the addition of a nanoemulsion of paraffin, as performed by Mantanis \&
Papadopoulos (2010). However, paraffin was not used in the present study to only analyze the influence of $\mathrm{SiO}_{2}$ nanoparticles on the thickness swelling of the particleboard.

However, it is important to note that the addition of nanoparticles decreased the thickness swelling in the panel by $42 \%$. This result was markedly different as it produced a significant difference at the $5 \%$ significance level. Therefore, the addition of the nanoparticles in the adhesive increased the dimensional stability of the panel.

Roumeli et al. (2012) found that swelling ranged from $27.07 \%$ to $28.41 \%$ in MDP treated with silica nanoparticles, while $29.63 \%$ swelling occurred in untreated MDP. Thus, as observed in this study, this characteristic was improved.

Table 2 shows the mean and standard deviation of the results of the mechanical tests of static bending and perpendicular tension. 
TABLE 2. Results of mechanical tests.

\begin{tabular}{|c|c|c|c|}
\hline \multirow{2}{*}{ Situations } & \multicolumn{2}{|c|}{ Static Bending } & \multirow{2}{*}{$\begin{array}{c}\text { Perpendicular Tension } \\
\text { (MPa) }\end{array}$} \\
\hline & MOR (MPa) & MOE (MPa) & \\
\hline \multirow{2}{*}{$0 \% \mathrm{SiO}_{2}$-Nano } & $12.4 a^{1}$ & $1937 \mathrm{a}$ & $0.63 \mathrm{a}$ \\
\hline & $(30 \%)^{2}$ & $(34 \%)$ & $(46 \%)$ \\
\hline \multirow{2}{*}{$4 \% \mathrm{SiO}_{2}-\mathrm{Nano}$} & $12.3 \mathrm{a}$ & $2400 \mathrm{a}$ & $0.79 \mathrm{a}$ \\
\hline & $(25 \%)$ & $(26 \%)$ & $(48 \%)$ \\
\hline
\end{tabular}

${ }^{1}$ Means followed by the same letter were not significantly different at a 5\% significance level.

${ }^{2}$ Values in parentheses show the coefficient of variation.

The addition of $\mathrm{SiO}_{2}$ nanoparticles showed no significant difference in the modulus of rupture (MOR) of the panel at a significance level of 5\%. EN 312 (2003) specifies a minimum MOR value of $13 \mathrm{MPa}$ for panels with thickness ranging between 6 and $13 \mathrm{~mm}$ to be suitable for use in dry conditions, including furniture (P2). The results of this study were close to the values required by the standard thresholds.

A study by Taghiyari \& Bibalan (2013) investigating the addition of copper nanoparticles in MDP panels resulted in MOR values between 11.55 and $12.19 \mathrm{MPa}$, similar to those presented in this work. In another study by Roumeli et al. (2012), using $\mathrm{SiO}_{2}$ nanoparticles in MDP panels, resulted in MOR values between 14.52 and $15.09 \mathrm{MPa}$, i.e., $18.5 \%$ higher than those obtained in this work.

The modulus of elasticity (MOE) also showed no significant difference at a significance level of 5\%. EN 312 (2003) specifies a minimum MOE value of $1800 \mathrm{MPa}$ for panels with thickness ranging between 6 and $13 \mathrm{~mm}$ for use in dry conditions, including furniture ( $\mathrm{P} 2)$. The values obtained in this study were above those required by the EN, especially for the panels produced with $\mathrm{SiO}_{2}$ nanoparticles.

From static bending results, adding $\mathrm{SiO}_{2}$ nanoparticles to the adhesive did not change the MOR and MOE of the particleboard because they were statistically equal.

Regarding the perpendicular tension test, the addition of nanoparticles also showed no significant difference at a significance level of 5\%. In EN 312 (2003), the minimum perpendicular tension should be $0.40 \mathrm{MPa}$. The results of this study were higher than the minimum required by the standard.

Taghiyari \& Bibalan (2013) used copper nanoparticles in the treatment of MDP panels and found a value of $0.48 \mathrm{MPa}$ for the perpendicular tension. Kumar et al. (2013) treated MDF with aluminum oxide nanoparticles and determined values for perpendicular tension to be 0.89 MPa. Roumeli et al. (2012) treated MDP panels with $\mathrm{SiO}_{2}$ nanoparticles and obtained a perpendicular tension value of $0.72 \mathrm{MPa}$. Therefore, the results obtained in this study were within the values found in the literature.

Thus, the addition of $\mathrm{SiO}_{2}$ nanoparticles did not influence the perpendicular tension particleboard.

\section{CONCLUSIONS}

Based on the results of this preliminary study, the addition of $\mathrm{SiO}_{2}$ nanoparticles to urea-formaldehyde-based adhesive increased the resistance to thickness swelling of the particleboard by $42 \%$, thereby improving the dimensional stability of the panel. However, the absence of paraffin emulsion impaired the results.
Likewise, there were no changes in the mechanical properties of the panels as the addition of $\mathrm{SiO}_{2}$ nanoparticles did not alter the properties of MOR, MOE, and perpendicular tension.

Therefore, adding $\mathrm{SiO}_{2}$ nanoparticles to the adhesive used to produce wood particleboards is a good option for improving the dimensional stability of the panels without decreasing its mechanical properties, even when used in small proportions, as demonstrated in this study.

Future studies should investigate the effects of adding higher percentages of $\mathrm{SiO}_{2}$ nanoparticles as well as adding a paraffin emulsion mixed with the adhesive and nanoparticles.

\section{REFERENCES}

Christoforo AL, Silva SAM da, Barbosa JC, Ribeiro Filho SLM, Panzera TH, Lahr FAR (2015) Produção de chapas de partículas com resíduos de madeira Cordia goeldiana. Engenharia Agrícola 35(2):368-377. DOI:

http://dx.doi.org/10.1590/1809-4430

Christoforo AL, Nascimento MF do, Panzera TH, Ribeiro Filho SLM, Lahr FAR (2016) Homogeneous Pinus sp. particle boards reinforced with laminated composite materials. Engenharia Agrícola 36(3):558-565. DOI: http://dx.doi.org/10.1590/1809-4430

European Committee for Standardization (2003) European Standard EN 312: Particleboard - Specifications.

European Committee for Standardization (2000) European Standard EN 310: Wood-based panels - Determination of modulus of elasticity in bending and bending strength.

European Committee for Standardization (2000) European Standard EN 317: Wood-based panels - Determination of swelling in thickness after immersion in water.

European Committee for Standardization (2000) European Standard EN 322: Wood-based panels - Determination of moisture content.

European Committee for Standardization (2000) European Standard EN 323: Wood-based panels - Determination of density.

European Committee for Standardization (2003) European Standard EN 1058. Wood-based panels - Determination of characteristic 5 percentile values and characteristic mean values.

Ferreira BS, Silva JVF, de Campos CI (2017) Static bending strength of heat-treated and chromated copper arsenate-treated plywood. BioResources 12(3):6276-6282. DOI: http://dx.doi.org/10.15376/biores.12.3.6276-6282 
Goveia D, Pinheiro JP, Milkova V, Rosa AH, van Leeuwen HP (2011) Dynamics and heterogeneity of Pb(II) binding by $\mathrm{SiO}_{2}$ nanoparticles in an aqueous dispersion. Langmuir 27(12):7877-7883. DOI: http://dx.doi.org/10.1021/la2008182.

Iwakiri S, de Matos JLM, Trianoski R, Prata JG (2012) Produção de painéis aglomerados homogêneos e multicamadas de Melia azedarach (Cinamomo) e Pinus taeda com diferentes teores de resina. Cerne 18(3):465-470.

Kumar A, Gupta A, Sharma KV, Nasir M (2013) Use of aluminum oxide nanoparticles in wood composites to enhance the heat transfer during hot-pressing. European Journal of Wood and Wood Products 71(2):193198. DOI: http://dx.doi.org/10.1007/s00107-013-0664-9

Lubis MAR, Park B-D, Lee S-M (2017) Modification of urea-formaldehyde resin adhesives with blocked isocyanates using sodium bisulfite. International Journal of Adhesion and Adhesives 73:118-124. DOI: http://dx.doi.org/10.1016/j.ijadhadh.2016.12.001

Mantanis GI, Papadopoulos AN (2010) Reducing the thickness swelling of wood based panels by applying a nanotechnology compound. European Journal of Wood and Wood Products 68(2):237-239. DOI: http://dx.doi.org/10.1007/s00107-009-0401-6

Nosál' E, Reinprecht L (2017) Anti-bacterial and anti-mold efficiency of $\mathrm{ZnO}$ nanoparticles present in melaminelaminated surfaces of particleboards. BioResources 12(4):7255-7267. DOI: http://dx.doi.org/10.15376/biores.12.4.7255-7267

Rangavar H, Hoseiny Fard MS (2015) The effect of nanocopper additions in a urea-formaldehyde adhesive on the physical and mechanical properties of particleboard manufactured from date palm waste. Mechanics of Composite Materials 51(1):119-2015. DOI: http://dx.doi.org/10.1007/s11029-015-9482-y
Rangel L, Moreno P, Trejo S, Valero S (2017)

Propiedades de tableros aglomerados de partículas fabricados con madera de eucalyptus urophylla. Maderas. Ciencia y tecnología 19(3):373-386. DOI: http://dx.doi.org/10.4067/S0718-221X2017005000032

Roumeli E, Papadopoulou E, Pavlidou E, Vourlias G, Bikiaris D, Paraskevopoulos KM, Chrissafis K (2012) Synthesis, characterization and thermal analysis of ureaformaldehyde $/ \mathrm{nanoSiO}_{2}$ resins. Thermochimica Acta 527(1):33-39. DOI: http://dx.doi.org/10.1016/j.tca.2011.10.007

Silva LCL, Lima FO, Chahud E, Christoforo AL, Lahr FAR, Favarim HR, Campos CI (2019) Heat transfer and physical-mechanical properties analysis of particleboard produced with $\mathrm{ZnO}$ nanoparticles addition. BioResources 14(4):9904-9915. DOI:

http://dx.doi.org/10.15376/biores.14.4.9904-9915

Taghiyari HR, Bibalan OF (2013) Effect of copper nanoparticles on permeability, physical, and mechanical properties of particleboard. European Journal of Wood and Wood Products 71(1):69-77. DOI: http://dx.doi.org/10.1007/s00107-012-0644-5

Taghiyari HR, Moradi-Malek B, Kookandeh MG, Bibalan OF (2014) Effects of silver and copper nanoparticles in particleboard to control Trametes versicolor fungus. International Biodeterioration \& Biodegradation 94(1):69-72. DOI: http://dx.doi.org/10.1016/j.ibiod.2014.05.029

Zeki C, Akbulut T (2015) Physical and mechanical properties of nanoreinforced particleboard composites. Maderas: Ciencia y Tecnología 17(2):319-334. DOI: http://dx.doi.org/10.4067/S0718-221X2015005000030 